Manuscript Number: COST-D-16-00182R1

Title: Pultruded GFRP double-lap single-bolt tension joints - temperature effects on mean and characteristic failure loads and stresses and knockdown factors

Article Type: Full Length Article

Keywords: Bolts; GFRP; joints; pultrusion; strength; temperature

Corresponding Author: Dr Geoffrey Turvey,

Corresponding Author's Institution: Lancaster University

First Author: Geoffrey Turvey

Order of Authors: Geoffrey Turvey; Anish Sana

Abstract: Details are presented of the fabrication and testing of five groups of twenty-four nominally identical double-lap single-bolt tension joints in pultruded glass fibre reinforced polymer (GFRP) composite plate. All of the joints had the same nominal width (W) to hole to diameter (D) ratio, but each of the five groups had a different end distance (E) to diameter ratio. Each group of twenty-four joints was divided into four sub-groups of six joints, which were tested at four temperatures. Tensile loads and overall extensions at failure and failure modes were recorded for each joint test. The test data was used to produce graphs of mean and characteristic failure stresses, as well as approximate mean and characteristic failure strains. The former data were used in conjunction with mean and characteristic failure stresses of the virgin GFRP plate to provide tensile knock-down factors for the bolted joints for five joint geometries and four test temperatures. The knockdown factors are potentially useful for preliminary joint design.

Response to Reviewers: Date: Mar 28, 2016

To: "Geoffrey Turvey" g.turvey@lancaster.ac.uk

cC: ; sanaalulstudents.ecu.edu

From: "Composite Structures" costdelsevier.com

Subject: Your Submission

Ms. Ref. No.: COST-D-16-00182

Title: Pultruded GFRP double-lap single-bolt tension joints - temperature effects on mean and characteristic failure loads and strengths and knockdown factors

Composite structures

Dear Dr Geoffrey Turvey,

The reviewers have commented on your above paper. They indicated that it is not acceptable for publication in its present form. 
However, if you feel that you can suitably address the reviewers' comments (included below), I invite you to revise and resubmit your manuscript.

Please carefully address the issues raised in the comments.

If you are submitting a revised manuscript, please also:

a) outline each change made (point by point) as raised in the reviewer comments

$\mathrm{AND} / \mathrm{OR}$

b) provide a suitable rebuttal to each reviewer comment not addressed

To submit your revision, please do the following:

1. Go to: http://ees.elsevier.com/cost/

2. Enter your login details

3. Click [Author Login]

This takes you to the Author Main Menu.

4. Click [Submissions Needing Revision]

Please note that this journal offers a new, free service called

Audioslides: brief, webcast-style presentations that are shown next to published articles on ScienceDirect (see also

http://www.elsevier.com/audioslides). If your paper is accepted for publication, you will automatically receive an invitation to create an Audioslides presentation.

Composite Structures features the Interactive Plot Viewer, see: http://www.elsevier.com/interactiveplots. Interactive Plots provide easy access to the data behind plots. To include one with your article, please prepare a .csv file with your plot data and test it online at http://authortools.elsevier.com/interactiveplots/verification before submission as supplementary material.

I look forward to receiving your revised manuscript.

Yours sincerely,

Antonio J. M. Ferreira

Editor

Composite structures

Note: While submitting the revised manuscript, please double check the author names provided in the submission so that authorship related changes are made in the revision stage. If your manuscript is accepted, any authorship change will involve approval from co-authors and respective editor handling the submission and this may cause a significant delay in publishing your manuscript 
Reviewer \#1: This paper presents an experimental study of pultruded GFRP double-lap, single-bolt, tension joints. The effects of end distance to hole diameter ratio, and temperature are investigated via a test programme involving 120 tests.

The tests appear to have been carried out in a competent manner, and the results follow reasonable trends. However, the presentation of the data is repetitive and mundane, and provides little insight into the motivation for the work or the results obtained. The manuscript reads more like an internal industry test report than a scientific paper. Some specific points:

1. Sections are not numbered, which makes it hard to follow the structure. In particular, the results should be separated from the test set-up, not lumped together in the section "Joint test setups, test procedure and test results".

2. $\quad 3 \mathrm{Nm}$ is quite a high value for "finger-tight" (must be very strong fingers...). $0.5-1.0 \mathrm{Nm}$ is a more common range when speaking of fingertight.

3. Figures 2 and 3 are unnecessary, as is Figure 5.

4. The method used to evaluate strain is very questionable. There is a standard method for this using extensometers in ASTM standard D 5961/D 5961M- 96, "Standard test method for bearing response of polymer matrix composite laminates", 1996. See papers which have used this method, for example:

Warren, K. C., et al. (2015). "Behavior of three-dimensional woven carbon composites in single-bolt bearing." Composite Structures 127: 175-184. or:

McCarthy, M. A., et al. (2002). "Bolt-hole clearance effects and strength criteria in single-bolt, single-lap, composite bolted joints." Composites Science and Technology 62(10-11): 1415-1431.

5. Some motivation should be provided for the chosen test temperatures.

6. Essentially the same data is presented in five different ways in Figs 7(a), (b), Figs 8(a), (b) and Table 2. Stress or load should be used but not both. Error bars should be used on the figure, which then makes Table 2 redundant.

7. The meaning and motivation of the "characteristic failure stress" is not given.

8. Figs. 11-13 are identical in trends to Figs. 7-9. There is certainly no need for Part (b) of these figures. The data would be best presented in tabular form.

9. It is not clear why the knock-down factors for the stresses should be different from the loads.

10. There is no discussion on the reasons for the any of the observed behaviour. Significant improvement in the discussion is needed.

Authors' responses to Reviewer $\sim 1$ 's comments:- 
1. Each section of the paper has now been numbered. In addition, the title of the paper has been amended slightly.

2. The comment that "finger-tight" is equivalent to a torque of $3 \mathrm{Nm}$ has been removed. It is simply stated that a calibrated torque wrench was used to tighten the bolts to a torque of $3 \mathrm{Nm}$.

3. Figures 2, 3 and 5 have been deleted. Moreover, the total number of figures has been reduced from 13 to 8 and the total number of tables has been reduced from 6 to 4 .

4. The authors accept that their method of determining the overall failure strain is not perfect. Indeed, they point out in the text that it is only approximate. The reviewer implies that using extensometers, as advocated in ASTM standard D 5961/D 5961M- 96, "Standard test method for bearing response of polymer matrix composite laminates", 1996, is an alternative method that is used to estimate the bearing failure strain of composite laminates. In both of the papers cited, which use extensometers to measure the extensional strain at failure, it is questionable whether bearing failure strain is actually being determined. The test specimens used in the papers had single-lap rather than double-lap configurations (as used in the present paper). Consequently, the specimens were loaded in combined bending and tension rather than axial tension, so that the material in contact the bolt shank was subjected a stress distribution which varied through the thickness of the laps. This is confirmed by the fact that the bolts rotated when the joints failed. Hence, the bearing stress at failure would be more localised than that produced in the double-lap joint tests of the present paper. Furthermore, in the two cited papers, the geometry of the test specimens was chosen to promote bearing failure, i.e. large E/D and W/D values (typically equal to 6), and eliminate any of the other failure modes (cleavage, shear and tension). In the present paper a range of joint geometries were considered and an estimate of the overall failure strain of each singlebolt double-lap joint was determined.

5. The text has been extended to point out that the particular range of temperatures selected for the joint tests was influenced by information provided in the Strongwell Design Manual for pultrusions. In that document, it is recommended that pultruded GFRP material should not be used in environments in which the temperature is greater than 650C. This guidance is based on information provided by the suppliers of the polymer matrix material and is not based on testing pultruded GFRP composite material. It was, therefore, decided to carry out joint tests for three temperatures below the recommended maximum temperature. Consequently, ambient (circa 200C), 400C, and 600C were chosen as being suitable test temperatures with the latter temperature $50 \mathrm{C}$ below the recommended maximum temperature. In addition, it was also decided to carry out tests at one temperature above the recommended maximum temperature, in order to see whether there was a significant reduction in the joints' failure loads. Consequently, the fourth test temperature selected was $800 \mathrm{C}$.

6. We accept the comment that it is preferable to present the test results either in terms of loads or stresses, but not both. We have, therefore, decided to present the test data in terms of stresses. However, we believe it is helpful to present the stress data both as functions of E/D and test temperature, as this information could be used easily for preliminary joint design, without the need to interpolate between the failure stresses (given as functions of E/D) to determine how 
they vary with temperature. We prefer not to eliminate Table 2, since providing numerical values helps the reader to replot the data, if required, at a larger scale than that used in the paper. However, we have removed the stresses from Table 2 and added cross-sectional areas so that, if required, the reader may also compute stresses. Hence, loads are only given in Table 2 and the focus of the graphical results presented is on stresses and strains. Consequently, the numbers of figures and tables have been reduced from 13 to 8 and 6 to 4, respectively. Finally, we do not agree that we should add upper and lower bounds to the data points on the graphs, as it would make them more difficult to appreciate, especially where data points are close to each other. We believe that including the values of the standard deviations in Table 2 is sufficient.

7. The meaning of the characteristic failure stress and the motivation for its inclusion are clarified. It is explained that characteristic failure stresses, determined on a statistical basis according to the number of replicate joints tested for each joint geometry and test temperature, are used to obtain failure stresses for use in joint design. Ultimate design stresses (strengths) in European limit state design codes (Eurocodes) are determined by dividing the characteristic stresses by reduction factors (according to the particular operating environment) greater than unity. Hence, characteristic stresses serve a useful purpose in design.

8. We have addressed this point in a different way, i.e. by deleting all of the graphs and tables for loads. However, as explained under point 6, we have retained the stress/strain vs temperature plots. Also, we have retained Table 2 but have modified it by deleting the mean stresses and adding the mean cross-sectional areas, so that the reader may produce large scale stress data, if required.

9. The knock-down factors for the stresses differ from those of the loads, because the stresses are derived quantities. Whilst the crosssectional areas of the joints are nominally identical, i.e. $40 \mathrm{~mm} \times 6.35$ $\mathrm{mm}=254 \mathrm{~mm} 2$, the widths and thicknesses of the joint half-laps were measured at three locations along their lengths and the means of these dimensions were used to calculate mean cross-sectional areas. These were then used as divisors to determine mean failure stresses from the mean failure loads. The mean of the six failure stresses for six nominally identical joints for the particular E/D and test temperature was then determined. This was then used in conjunction with its standard deviation to determine the characteristic failure stress. The additional processing stage, that is the calculation of different mean cross-sectional areas for each E/D ratio to determine the characteristic stresses, is not required to determine the characteristic loads and this explains why the knock-down factors for characteristic loads and stresses differ slightly. However, as the knock-down factors for the failure loads have been removed from the revised paper, any such misunderstanding will no longer arise.

10. We believe the the descriptions of joint failure tests and the results derived therefrom are presented in sufficient detail and do not require "reasons for observed behaviour". For example, the mean failure stresses tend to reduce linearly over temperature range for E/D ratios from 2 - 4. This is an observed fact based on the test data. There is no obvious reason, supported by the test data, why this should be so. Hence, the authors believe that trying to give reasons for this, would be entering the "realms of conjecture" and therefore unscientific. 

Engineering Department, Lancaster University, Gillow Avenue,

Bailrigg,

Lancaster,

LA1 4YW.

$11^{\text {th }}$ May, 2016.

Professor Antonio Ferreira,

Editor,

Composite Structures.

Dear Antonio,

Pultruded GFRP double-lap single-bolt tension joints - temperature effects on mean and characteristic failure stresses and knock-down factors [Revised Title]

Please would you kindly arrange for our revised paper, entitled as above, to be re-considered for publication in Composite Structures. It has not been submitted to any other journal for possible publication.

Please note that the text changes in the revised paper are coloured red to make them easier to identify. The overall length of the text has been reduced by reducing the numbers figures and tables, as explained in the “Authors' Responses to Reviewer \#1's Comments".

I look forward to receiving your decision on our revised paper's acceptability or otherwise for publication in due course.

Yours sincerely,

Geoff Turvey 


\section{Authors' responses to Reviewer \#1's comments}

Authors' Responses to Reviewer \#1's Comments rev 1.doc

\section{Authors' Responses to Reviewer 1's Comments:-}

1. Each section of the paper has now been numbered. In addition, the title of the paper has been amended slightly.

2. The comment that "finger-tight" is equivalent to a torque of $3 \mathrm{Nm}$ has been removed. It is simply stated that a calibrated torque wrench was used to tighten the bolts to a torque of $3 \mathrm{Nm}$.

3. Figures 2, 3 and 5 have been deleted. Moreover, the total number of figures has been reduced from 13 to 8 and the total number of tables has been reduced from 6 to 4 .

4. The authors accept that their method of determining the overall failure strain is not perfect. Indeed, they point out in the text that it is only approximate. The reviewer implies that using extensometers, as advocated in ASTM standard D 5961/D 5961M- 96, "Standard test method for bearing response of polymer matrix composite laminates", 1996, is an alternative method that is used to estimate the bearing failure strain of composite laminates. In both of the papers cited, which use extensometers to measure the extensional strain at failure, it is questionable whether bearing failure strain is actually being determined. The test specimens used in the papers had single-lap rather than double-lap configurations (as used in the present paper). Consequently, the specimens were loaded in combined bending and tension rather than axial tension, so that the material in contact the bolt shank was subjected a stress distribution which varied through the thickness of the laps. This is confirmed by the fact that the bolts rotated when the joints failed. Hence, the bearing stress at failure would be more localised than that produced in the double-lap joint tests of the present paper. Furthermore, in the two cited papers, the geometry of the test specimens was chosen to promote bearing failure, i.e. large E/D and W/D values (typically equal to 6), and eliminate any of the other failure modes (cleavage, shear and tension). In the present paper a range of joint geometries were considered and an estimate of the overall failure strain of each single-bolt double-lap joint was determined.

5. The text has been extended to point out that the particular range of temperatures selected for the joint tests was influenced by information provided in the Strongwell Design Manual for pultrusions. In that document, it is recommended that pultruded GFRP material should not be used in environments in which the temperature is greater than $65^{\circ} \mathrm{C}$. This guidance is based on information provided by the suppliers of the polymer matrix material and is not based on testing pultruded GFRP composite material. It was, therefore, decided to carry out joint tests for three temperatures below the recommended maximum temperature. Consequently, ambient (circa $20^{\circ} \mathrm{C}$ ), $40^{\circ} \mathrm{C}$, and $60^{\circ} \mathrm{C}$ were chosen as being suitable test temperatures with the latter temperature $5^{\circ} \mathrm{C}$ below the recommended maximum temperature. In addition, it was also decided to carry out tests at one temperature above the recommended maximum temperature, in order to see whether there was a significant reduction in the joints' failure loads. Consequently, the fourth test temperature selected was $80^{\circ} \mathrm{C}$.

6. We accept the comment that it is preferable to present the test results either in terms of loads or stresses, but not both. We have, therefore, decided to present the test data in terms of stresses. However, we believe it is helpful to present the stress data both as functions of E/D and test temperature, as this information could be used easily for preliminary joint design, without the need to interpolate between the failure stresses (given as functions of E/D) to determine how they vary with temperature. We prefer not to eliminate Table 2, since providing numerical values helps the reader to replot the data, if required, at a larger scale than that used in the paper. However, we have removed the stresses from Table 2 and added cross-sectional areas so that, if required, the reader may also compute stresses. Hence, loads are only given in Table 2 and the focus of the graphical results presented is on stresses and strains. Consequently, the numbers of figures and tables have been reduced from 13 to 8 and 6 to 4, respectively. Finally, we do not agree that we should add upper and lower bounds to the data points on the graphs, as it would make them more difficult to appreciate, especially where data points are close to each other. We believe that including the values of the standard deviations in Table 2 is sufficient.

7. The meaning of the characteristic failure stress and the motivation for its inclusion are clarified. It is explained that characteristic failure stresses, determined on a statistical basis according to the number of replicate joints tested for each joint geometry and test temperature, are used to obtain failure stresses for use in joint design. Ultimate design stresses (strengths) in European limit state design codes (Eurocodes) are determined by dividing the characteristic stresses by reduction factors (according to the particular operating environment) greater than unity. Hence, characteristic stresses serve a useful purpose in design.

8. We have addressed this point in a different way, i.e. by deleting all of the graphs and tables for loads. However, as explained under point 6 , we have retained the stress/strain vs temperature plots. Also, we have 
retained Table 2 but have modified it by deleting the mean stresses and adding the mean cross-sectional areas, so that the reader may produce large scale stress data, if required.

9. The knock-down factors for the stresses differ from those of the loads, because the stresses are derived quantities. Whilst the cross-sectional areas of the joints are nominally identical, i.e. $40 \mathrm{~mm} \times 6.35 \mathrm{~mm}=254$ $\mathrm{mm}^{2}$, the widths and thicknesses of the joint half-laps were measured at three locations along their lengths and the means of these dimensions were used to calculate mean cross-sectional area of each half-lap. These were then used as divisors to each of the failure loads to determine their failure stresses. The mean of the six failure stresses was then determined for the particular E/D and test temperature. This was then used in conjunction with its standard deviation to determine the characteristic failure stress. The foregoing calculation steps meant that different mean cross-sectional areas (rather than nominal cross-sectional areas) were determined for each E/D ratio. Hence, the characteristic stresses are not directly related to the characteristic loads. This explains why the knock-down factors for characteristic loads and stresses differ slightly. However, as the knock-down factors for the failure loads have been removed from the revised paper and, therefore, this misunderstanding will no longer arise.

10. We believe the descriptions of joint failure tests and the results derived therefrom are presented in sufficient detail and do not require "reasons for observed behaviour". For example, the mean failure stresses tend to reduce linearly over temperature range for E/D ratios from 2 - 4. This is an observed fact based on the test data. There is no obvious reason (revealed by the test data) why this relationship should be linear rather nonlinear. Hence, the authors believe that trying to give reasons/explanations for this and other observations would be entering the "realms of conjecture" and, therefore, be unscientific. 
Click here to view linked References

Title Page.doc

Pultruded GFRP double-lap single-bolt tension joints - temperature effects on mean and characteristic failure stresses and knock-down factors

by

$$
\text { G.J. Turvey }{ }^{\mathrm{a}, *} \text { and A. Sana }{ }^{\mathrm{a}, \mathrm{b}}
$$

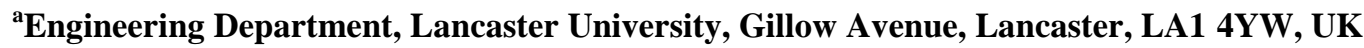
${ }^{\mathrm{b}}$ Department of Computer Science, College of Science \& Technology, East Carolina University, Greenville, NC - 27858, USA

(*Corresponding author) 


\title{
Pultruded GFRP double-lap single-bolt tension joints - temperature effects on mean and characteristic failure stresses and knock-down factors
}

by

\author{
G.J. Turvey ${ }^{\mathrm{a}, *}$ and A. Sana ${ }^{\mathrm{a}, \mathrm{b}}$ \\ ${ }^{a}$ Engineering Department, Lancaster University, Gillow Avenue, Lancaster, LA1 4YW, UK \\ ${ }^{b}$ Department of Computer Science, College of Science \& Technology, East Carolina University, \\ Greenville, NC - 27858, USA \\ (*Corresponding author)
}

\begin{abstract}
Details are presented of the fabrication and testing of five groups of twenty-four nominally identical double-lap single-bolt tension joints in pultruded glass fibre reinforced polymer (GFRP) composite plate. All of the joints had the same nominal width (W) to hole to diameter (D) ratio, but each of the five groups had a different end distance (E) to diameter ratio. Each group of twenty-four joints was divided into four sub-groups of six joints, which were tested at four temperatures. Tensile loads and overall extensions at failure and failure modes were recorded for each joint test. The test data was used to produce graphs of mean and characteristic failure stresses, as well as approximate mean and characteristic failure strains. The former data were used in conjunction with mean and characteristic failure stresses of the virgin GFRP plate to provide tensile knock-down factors for the bolted joints for five joint geometries and four test temperatures. The knock-down factors are potentially useful for preliminary joint design.
\end{abstract}

Keywords: Bolts; GFRP; joints; pultrusion; strength; temperature

\section{Introduction}

The behaviour of pultruded glass fibre reinforced polymer (GFRP) composite bolted tension joints used in construction applications has been the subject of a number of research studies since the early 1990s. In particular, Abd-El-Naby and Hollaway [1], Rosner and Rizkalla [2], Cooper and Turvey [3] and Turvey and Cooper [4] between them carried out several hundred double-lap single-bolt tension joint tests on pultruded GFRP composite plate and wide flange (WF) sections in order to quantify the effects of joint geometry, i.e. end distance (E) and width (W) to bolt/hole diameter (D), on their failure loads and stresses. Subsequently, Abd-ElNaby and Hollaway [5] and Hassan et al. [6] reported failure loads and stresses for double-lap multi-bolt joints in pultruded GFRP composite plate. In all of the foregoing experimental studies the tensile load was applied along the joint's longitudinal axis of symmetry and was parallel to the rovings within the GFRP material. The effects of off-axis loading on the failure loads of double-lap single-bolt tension joints were reported in a study by Turvey [7].

In each of the experimental studies cited above, the double-lap single- and multi-bolt tension joints were tested to failure under ambient temperature conditions. A study of double-lap single-bolt tension joints subjected to hot and hot-wet preconditioning was reported more recently by Turvey and Wang [8]. However, the tests were undertaken for only four joint geometries: (W/D = 7, $\mathrm{E} / \mathrm{D}=5),(\mathrm{W} / \mathrm{D}=5, \mathrm{E} / \mathrm{D}=2),(\mathrm{W} / \mathrm{D}=10, \mathrm{E} / \mathrm{D}=2)$ and $(\mathrm{W} / \mathrm{D}=3, \mathrm{E} / \mathrm{D}=7)$ which, at ambient temperature, failed in bearing, cleavage, shear and tension modes, respectively. Furthermore, in [9] Turvey and Wang used a Taguchi analysis of joint test data to quantify the degrading effects of bolt/hole clearance, angle between the tension and pultrusion directions, elevated temperature and water immersion period on the failure loads of double-lap single-bolt tension joints. The analysis showed that temperature was the dominant factor reducing the joints' failure loads.

Although the joint test results and conclusions reported in [8] and [9] are important, the range of geometries and temperatures investigated were insufficient to enable design data to be compiled. Therefore, it was decided to undertake a more extensive series of double-lap single-bolt tension joint tests in order to quantify the effects of temperature and joint geometry on their failure loads and stresses. Moreover, it was intended that the test data would be sufficient to enable characteristic values and knock-down factors to be determined for the preliminary design of these joints. 
The purpose of the present paper is to present and describe the results of the experimental investigation. In so doing, the elastic modulus and failure stresses of the virgin pultruded GFRP composite plate are presented first. Thereafter, details of the geometries of the joints and the range of test temperatures are explained, together with the number of nominally identical joints for each combination of geometry and temperature. This is followed by a description of the test setup, the test procedure and the data recorded during each joint test. Mean values of failure loads and overall extensions at failure. are presented in tabular format. Graphs of the mean failure stresses of the joints are then presented as functions of joint geometry and test temperature and their salient features are identified. Characteristic joint failure stresses are also presented for preliminary joint design and to complement their corresponding mean values. The final sets of results are knock-down factors which quantify the mean and characteristic failure stresses of the joints relative to those of the virgin pultruded GFRP plate. The paper is concluded with a summary of the main observations from the test results.

\section{Properties of the virgin pultruded GFRP composite plate}

The pultruded GFRP polymer composite used in the double-lap single-bolt joint tests was $E X T R E N^{\circledR} 500$ series material. It is stocked as flat plates (often referred to as boards) approximately $2400 \mathrm{x} 1200 \mathrm{~mm}$ and is available in thicknesses of $3.2 \mathrm{~mm}$ up to $25.4 \mathrm{~mm}$. The thickness of the GFRP plate selected for the present joint tests was $6.4 \mathrm{~mm}$. Minimum values of the elastic modulus and failure stress of the GFRP plate are given in the manufacturer's design manual [10]. The plate's modulus and failure stress are lower than those given for wide flange (WF), I, channel and angle sections because the fibre volume percentage is lower, typically about $40 \%$ compared to 50\%. Nevertheless, double-lap single-bolt tension joint tests reported in [3] and [4] suggest that, at room temperature (circa $20{ }^{\circ} \mathrm{C}$ ), the failure loads and stresses of plate joint tests may provide lower bound estimates for the failure loads and stresses of similar joints in WF etc. sections.

Four 300 x $25 \mathrm{~mm}$ rectangular coupons were cut out of the GFRP plate with their longer sides parallel to the rovings and were tested untabbed in axial tension to determine their failure loads and stresses. The mean failure load and stress were $46.92 \mathrm{kN}$ and $299.2 \mathrm{~N} / \mathrm{mm}^{2}$, respectively. The corresponding minimum values, based on the data in [10], are $32.86 \mathrm{kN}$ and $207 \mathrm{~N} / \mathrm{mm}^{2}$, respectively.

\section{Joint geometries, test matrix and fabrication details}

The general shape of the pultruded GFRP plates used to fabricate the inner lap of the tension joints is shown in Figure 1. The outer laps were formed by two $6.4 \mathrm{~mm}$ steel plates of the test fixture. In order to minimise the total number of joint tests, given that six nominally identical joints were to be tested for each of the chosen joint geometries, it was decided to keep the hole diameter D and the plate width $\mathrm{W}$ nominally constant at $10 \mathrm{~mm}$ and $40 \mathrm{~mm}$, respectively. In addition, the length $\mathrm{G}$ of the grip area and the distance $\mathrm{F}$ were also fixed at $50 \mathrm{~mm}$ and $100 \mathrm{~mm}$, respectively. On the other hand, the overall length $\mathrm{L}$ and the end distance $\mathrm{E}$ were variable in order to accommodate a range of end distance $\mathrm{E}$ to hole diameter $\mathrm{D}$ ratios.

The bolt diameter was chosen to be equal to the diameter $\mathrm{D}$ of the bolt hole, so that the bolts were nominally tight fitting. M10 steel bolts with smooth shanks were used in order to avoid thread contact with the cylindrical surface of the bolt hole. One steel washer was used under the bolt head and nut. A calibrated torque wrench was used to tighten each joint's bolt to a torque of $3 \mathrm{Nm}$. Although, higher torques have been shown to increase the load capacity of double-lap single-bolt joints, the increase in capacity is not directly proportional to the increase in torque and, moreover, its effect cannot be relied upon in the long term [3]. Hence, the failure stresses determined from the present series of joint tests may be deemed to be lower bound values for use in design.

The widths and thicknesses of each of the GFRP plates were measured at three locations along their lengths and used to determine their mean widths, thicknesses, and cross-sectional areas, with the latter being used in evaluating each joint's failure stress.

Five sets of GFRP plates were prepared for the joint tests, i.e. one for each of five E/D ratios, namely 2, 2.5, 3, 4 and 5, encompassing the range of values likely to arise in practice. Each set included twenty-four nominally identical plates, which were further sub-divided into four groups of six plates. Each group was to be tested at one of four temperatures, namely ambient (circa $20{ }^{\circ} \mathrm{C}$ ), $40{ }^{\circ} \mathrm{C}, 60{ }^{\circ} \mathrm{C}$ and $80{ }^{\circ} \mathrm{C}$. The rationale for selecting the first three temperatures is based on information provided in [10], which recommends that pultruded GFRP material should not be used in temperature environments above $65{ }^{\circ} \mathrm{C}$. However, this guidance is based on information provided by the suppliers of the polymer matrix material. It was, therefore, decided to carry out joint tests at three temperatures below the recommended maximum temperature. In addition, it was also decided to carry out joint tests at one temperature above the recommended maximum temperature, in order to see 
whether this would produce a significant reduction in the joints' failure loads. The fourth test temperature selected was $80{ }^{\circ} \mathrm{C}$. Therefore, a total of 120 joints were fabricated from the GFRP plates in accordance with the test matrix given in Table 1 .

A diamond coated wheel saw, mounted on an air bench to extract resin dust and glass fibre fragments during the cutting process, was used to cut the GFRP plates to the required dimensions prior to drilling the bolt holes. The bolt holes were drilled in each plate individually (rather than in a stack) using a bench mounted pillar drill. The GFRP plate was clamped to a wooden block positioned underneath it to limit delamination due to drill breakthrough. The rotational speed of the $10 \mathrm{~mm}$ diameter tungsten carbide tipped drill was approximately 900 revolutions per minute. A hand held vacuum was used to safely remove the small quantity of resin dust and fibre fragments produced during the drilling process.

\section{Joint test setups and test procedure}

Once cutting and drilling of the GFRP plates had been completed, joint testing at ambient temperature (circa 20 ${ }^{\circ} \mathrm{C}$ ) began. For these tests an existing steel fixture was used. The GFRP plate was bolted to the lower end of the fixture (the upper end of which was gripped by the upper grip of the test machine) and the bolt was torqued to 3 $\mathrm{Nm}$. The other end of the GFRP plate was gripped by the lower grip of the test machine (an INSTRON 8802, $256 \mathrm{kN}$ capacity machine) so that the joint could be tested to failure in tension.

Before starting to apply the tensile load to the joint, the distance between the grips was measured, in order to try to obtain an estimate of the overall strain to failure using the overall extension at the instant of failure recorded by the test machine. It is, of course recognised that the overall extension is the sum of the extensons of the steel and GFRP parts of the test setup. However, the former parts are much stiffer than the latter, so it might reasonably be anticipated that most of the overall extension at failure would be attributable to the extension of the GFRP plate. Moreover, the length F between the centre of the bolt hole and the nearer end of the grip zone was constant for all of the joints, and could be used as the gauge length for computing the extensional strain at failure of the GFRP joint. Obviously, a more accurate approach would be to measure the strain using back-toback strain gauges bonded to opposite faces of the GFRP plate, but this would have required 240 gauges and was deemed impractical in terms of both time and cost.

The double-lap single-bolt joints, tested at ambient temperature, were loaded to failure at a constant load rate of $2 \mathrm{kN} /$ minute. During each test the load and overall extension were recorded at 0.1 second intervals.

For the elevated temperature tests the test fixture for the ambient temperature tests had to be modified, because it was too long to fit between the grips inside the temperature cabinet and also because the upper grip could not accommodate its circular cross-section steel rod. The latter was replaced with a short flat rectangular steel plate, the thickness of which was approximately equal to that of the GFRP plate forming the joint. Figure 2 shows the modified test fixture.

The primary difference in the test procedure between the room temperature (circa $20{ }^{\circ} \mathrm{C}$ ) joint tests and the elevated temperature tests was that the latter joints were allowed to soak at the required test temperature (40, 60 or $80{ }^{\circ} \mathrm{C}$ ) for 20 minutes prior to loading them to failure. Previous work by Turvey and Wang [11] based on experiment and FE analysis has shown that this time period is sufficient for the whole of the joint to reach the test temperature.

\section{Failure loads obtained from joint tension tests}

From the load versus extension data of each pultruded GFRP double-lap single-bolt joint test, its failure load and associated overall extension could be determined. Furthermore, after removing each joint from the test machine and test fixture a photographic record was made of its failure mode. For each combination of end distance to hole diameter ratio (E/D) and test temperature six failure loads were obtained, i.e. one for each of the six nominally identical joints. From these loads the mean failure load and its standard deviation were computed. The mean failure load was then converted to the mean failure stress by dividing by the mean cross-sectional area of the six nominally identical joints. The mean values of the failure loads and associated approximate overall extensions are presented in Table 2.

\section{Effects of joint geoemtry and test temperature on mean failure stresses}


Figures 4(a) and 4(b) show the dependence of mean failure stress on joint geometry (E/D) and test temperature, respectively. It is evident in Figure 4(a) that, in general, the mean failure stresses increase almost linearly for all temperatures up to an E/D ratio of 3. Thereafter, the mean failure stressess of the joints tested at $20{ }^{\circ} \mathrm{C}$ appear to increase linearly, but at a lower rate up to $\mathrm{E} / \mathrm{D}=5$. However, for the higher test temperatures the mean failure stresses appear to level off between $\mathrm{E} / \mathrm{D}=4$ and $\mathrm{E} / \mathrm{D}=5$. This suggests that a bilinear design curve could be used to represent the effect of joint geometry (E/D) for joints tested at $20{ }^{\circ} \mathrm{C}$ and a trilinear curve for the higher test temperatures.

It is clear from Figure 4(b) that, for nearly all joint geometries (E/D), the mean failure stressess decrease linearly with increasing temperature. The exception to this is the mean failure stress of the joints with E/D $=4$ tested at $20{ }^{\circ} \mathrm{C}$ which appears to be somewhat low. In addition, it appears that the joints with geometries, E/D = 4 and $\mathrm{E} / \mathrm{D}=5$, exhibit essentially the same mean faiure stresses for temperatures between $40{ }^{\circ} \mathrm{C}$ and $80{ }^{\circ} \mathrm{C}$. Again, it is clear that design curves for the effect of increasing temperature on the joints' mean failure stresses could be represented by a series of straight lines of negative slope.

\section{Effects of joint geometry and test temperature on strains to failure}

As mentioned in Section 4, it was deemed impractical to use electrical resistance strain gauges to determine the failure strain of each joint tested - too many gauges would have been required. Nevertheless, for each joint test, it was possible to record the overall extension of the GFRP joint and test fixture at failure. If it is assumed that the axial stiffness of the GFRP bolted joint is much less than that of the steel components of the test fixture, then it may be expected that most of the overall extension to failure is due to the extension of the GFRP joint. Furthermore, the length F (see Figure 1) of the joint's GFRP plate was the same for all joints regardless of their E/D ratios. Therefore, it is not entirely unreasonable to use $\mathrm{F}(=100 \mathrm{~mm})$ as the gauge length for the overall extension at failure in order to determine - at least approximately - the joints' mean failure strains. Hence, upper bound mean failure strains may be determined simply by dividing the extensions in the rightmost column of Table 2 by $100 \mathrm{~mm}$. The computed strains to failure are plotted in Figures 5(a) and 5(b) as functions of the joint geometry (E/D) and test temperature, respectively.

Figure 5(a) suggests that, in general, the mean strains to failure of the joints tested at $20{ }^{\circ} \mathrm{C}$ are sigificantly lower than those of the joints tested at higher temperatures, except for the geometries corresponding to E/D = 2 and 2.5. Furthermore, the joints tested at 40,60 and $80{ }^{\circ} \mathrm{C}$ generally exhibit similar mean strains to failure, especially for E/D values greater than 2. Also, the mean failure strains of all of the joints increase as E/D increases.

Figure 5(b) shows that the mean failure strains of joints with $\mathrm{E} / \mathrm{D}=2.5$ to 5 vary in a roughly similar manner with increasing temperature, i.e. the mean strain increases as the test temperature increases from $20{ }^{\circ} \mathrm{C}$ to $40{ }^{\circ} \mathrm{C}$ and then remains roughly constant as the temperature increases to $80{ }^{\circ} \mathrm{C}$. Furthermore, but with the exception of joints with $\mathrm{E} / \mathrm{D}=2$, the mean failure strains tend to increase as $\mathrm{E} / \mathrm{D}$ increases from 2.5 to 5 .

\section{Effects of joint geometry and test temperature on failure modes}

For the joints with E/D ratios of 2 and 2.5 which were tested at $20{ }^{\circ} \mathrm{C}$ and $40{ }^{\circ} \mathrm{C}$ the shear failure mode was observed. On the other hand, joints with $\mathrm{E} / \mathrm{D}$ ratios of 4 and 5 exhibited the tension failure mode at test temeratures of $20{ }^{\circ} \mathrm{C}$ and $40{ }^{\circ} \mathrm{C}$. At the highest E/D ratios and test temperatures, the bearing failure mode tended to dominate. It was observed that for the lower E/D values cleavage failure modes were most common for all temperatures. Figure 6 shows one example of each of the four failure modes with the particular E/D ratios and test temperatures identified.

\section{Effects of joint geoemtry and test temperature on characteristic failure loads, stresses and strains}

BS EN 1990: 2002 [12] indicates that characteristic failure stresses may be determined from mean failure stresses, where the latter have been determined from a number of nominally identical material specimens or components. The characteristic failure stress is determined using Equation (1):-

$$
\sigma_{c}=\sigma_{m}-k\left(\sigma_{s t d}\right)
$$

In Equation (1) $\sigma_{c}$ is the characteristic failure stress of the material specimen/component, $\sigma_{m}$ is the mean failure stress of the total number of nominally identical specimens/components tested, and $\sigma_{s t d}$ is the standard 
deviation of the mean failure stress. The multiplication factor $k$ is determined according to the number of nominally identical specimens/components tested. $k$-values are given in Appendix D of [12]. As indicated in Table 1 six nominally identical joints were tested for each joint geometry (E/D) and test temperature and so $k=1.77$. However, in a few cases, indicated by an asterisk against the mean failure load in Table 2, only five of the six tests produced valid failure stresses and so $k=1.80$ was used in Equation (1) to evaluate their characteristic failure stresses. It should be appreciated that Equation (1) is equally valid for other quantities (provided the $\sigma$ symbols are interpreted as those quantities) and, therefore, it could also be used to determine characteristic failure loads and strains.

The motivation for determining the characteristic failure stresses from the joint tests was that they are needed to determine design stresses, which are used in limit state design codes, e.g. Eurocodes. The design stresses are obtained by dividing the characteristic stresses by factors, the values of which may differ according to the particular conditions of the design situation.

Figs. 7 and 8 constitute the characteristic values corresponding to Figs. 4 and 5, respectively. As the trends of the graphical data in Figs. 7 and 8 are similar to, but for lower values, than those in Figs. 4 and 5, they will simply be presented without further discussion in order to avoid repetition.

\section{Knock-down factors for mean and characteristic failure stresses}

It is well known that the tensile failure stresses of bolted joints in pultruded GFRP plate are signifcantly lower than those of the virgin plate, because the holes which accommodate the bolts not only disrupt the continuity of the glass fibre rovings, but also produce stress concentrations at the edges of the holes. From the standpoint of the structural engineer engaged in the design of bolted joints in pultruded GFRP structures, it is useful to have some idea of what the likely reduction in the failure stress might be for a given situation, before beginning the detailed joint design. The results of the present experimental investigation provide guidance on the failure stresses of double-lap single-bolt tension joints in pultruded GFRP plate - one of the simplest forms of joint, which is sometimes referred to as the building block for multi-bolt joint design. However, the failure stresses presented so far for these joints do not illustrate the reductions in these quantities relative to those of the virgin GFRP plate; these reductions are often referred to in terms of joint efficiencies or knock-down factors. The former terminology refers to the joint's failure stress divided by the corresponding failure stress of the virgin material and is expressed in percentage terms, whereas the latter terminology refers to the multiplication factor that has to be applied the the virgin material's failure stress to give the same failure stress for the bolted joint. Here, the latter approach is adopted. Thus, knock-down factors have been computed for failure stresses. It has been decided not to present knock-down factors for failure strains because the computed strains are approximate/upper bound values and, moreover, are of less interest from a practical standpoint.

Knock-down factors for mean and characteristic failure stresses are presented in Tables 3 and 4 as functions of joint geomerty and test temperature. The mean and characteristic failure stresses of the virgin GFRP plate were $299.19 \mathrm{~N} / \mathrm{mm}^{2}$ and $267.05 \mathrm{~N} / \mathrm{mm}^{2}$, respectively.

It should be appreciated that the knock-down factors in Tables 3 and 4 for the 40 to $80{ }^{\circ} \mathrm{C}$ temperatures have been determined using the virgin mean and characteristic stresses for the $20{ }^{\circ} \mathrm{C}$ test temperature. Ideally, the virgin mean and characteristic stresses for 40 to $80{ }^{\circ} \mathrm{C}$ test temperatures should have been used, but they were not available. Were this not so, then somewhat higher knock-down factors may well have been computed. Nevertheless, the present factors for these temperatures may constitute lower bound values for preliminary joint design.

\section{Concluding remarks}

Mean failure loads, stresses and overall extensions have been reported for 120 axial tension tests on double-lap single-bolt joints in pultruded GFRP plate with constant width to diameter ratios $(\mathrm{W} / \mathrm{D}=4)$ and a range of end distance to bolt/hole diameter ratios ( $\mathrm{E} / \mathrm{D}=2$ to 5$)$ and test emperatures $\left(20\right.$ to $\left.80{ }^{\circ} \mathrm{C}\right)$. It is shown that mean failure stresses increase as the E/D ratio increases and that the highest stresses are obtained with the lowest test temperature. The mean failure stress versus E/D ratio curves show that for test temperatures of $40{ }^{\circ} \mathrm{C}$ and above there is very little change in the mean failure stress between $E / D=4$ and 5 . Furthermore. The mean failure stresses tend to reduce linearly with increasing temperature for all E/D ratios with the dependence on increasing temperature being almost identical for $\mathrm{E} / \mathrm{D}=4$ and 5 . 
Mean failure strain has been shown to increase approximately linearly with increasing E/D ratio. However, the strains to failure are much lower for the $20{ }^{\circ} \mathrm{C}$ test temperature and are almost identical for the three higher temperatures. However, the plots of mean failure strain versus temperature show that the strain increases linearly between 20 and $40^{\circ} \mathrm{C}$ then, except for the $20^{\circ} \mathrm{C}$ test temperature, remains roughly constant with further increase in temperature.

The effects of E/D ratio and test temperature on the joints' characteristic failure stresses are similar to those observed for the mean failure stresses but, as expected, their values are somewhat smaller. A similar dependency was observed between the mean and characteristic failure strains.

The tabulated knock-down factors for mean and characteristic failure stresses are important for the preliminary design of double-lap single-bolt tension joints in pultruded GFRP plate. Their values tend to increase with increasing E/D ratio and reduce with increasing temperature. The values of the factors in Tables 3 and 4 enable the designer to see at a glance how much a joint's failure stress is reduced relative the virgin GFRP's failure stress for a particular joint geometry (E/D) and test temperature. Hence, the designer may use this information to decide whether or not to modify the joint's geometry (E/D). Finally, it should be appreciated that the knockdown factors for the $40-80{ }^{\circ} \mathrm{C}$ temperatures may be lower bound values, because they were computed using the virgin GFRP plate's failure stress for the $20^{\circ} \mathrm{C}$ test temperature - no values being available for higher temperatures.

\section{Acknowledgements}

The use of the Engineering Department's materials and structures testing equipment is gratefully acknowledged by the authors. They also wish to express their thanks to the Department's technician staff for their help and guidance in connection with the fabrication and testing of the bolted GFRP joints.

\section{References}

1. Abd-El-Naby SFM, Hollaway L. The experimental behaviour of bolted joints in pultruded glass/polyester material. part 1: single-bolt joints. Composites 1993;24:531-8.

2. Rosner C, Rizkalla, S. Bolted connections for fiber-reinforced composite structural members: experimental program. Journal of Materials in Civil Engineering 1995;7:223-31.

3. Cooper C, Turvey GJ. Effects of joint geometry and bolt torque on the structural performance of single bolt tension joints in pultruded GRP sheet material. Composite Structures 1995;32(1-4):217-26.

4. Turvey GJ, Cooper C. Single bolt tension joint tests on pultruded GRP WF-section web and flange material. Presented at ICCM-10, $14^{\text {th }}-18^{\text {th }}$ August, 1995, University of British Columbia, Canada. Published in The Tenth International Conference on Composite Materials, Vol.III, Processing and Manufacturing, Edited by A.

Poursartip and K. Street, Woodhead Publishing Limited, (1995), 621-8.

5. Abd-El-Naby SFM, Hollaway L. The experimental behaviour of bolted joints in pultruded glass/polyester material. part 2: two bolt joints. Composites 1993;24:539-46.

6. Hassan NK, Mohamedien MA, Rizkalla, SH. Multibolted joints for GFRP structural members. Journal of Composites for Construction 1997;1:3-9.

7. Turvey GJ. Single-bolt tension joint tests on pultruded GRP plate - effects of the orientation of the tension direction relative to pultrusion direction. Composite Structures 1998;42(4):341-51.

8. Turvey GJ, Wang P. Failure of PFRP single-bolt tension joints under hot-wet conditions. Composite Structures 2007;77(4):514-20.

9. Turvey GJ, Wang P. Failure of pultruded GRP bolted joints: a Taguchi analysis. Proceedings of the Institution of Civil Engineers: Engineering and Computational Mechanics 2009:162(EM3):155-66.

10. Anon, EXTREN fiberglass structural shapes design manual. Bristol, VA: Strongwell; 1989.

11. Turvey GJ, Wang P. Thermal preconditioning study for bolted tension joints in pultruded GRP plate.

Composite Structures 2007;77(4):509-13.

12. BSI, Eurocode. Basis of structural design (annex D) in BS EN 1990. British Standards Institution: London, $\mathrm{UK} ; 2002$. 


\section{List of Figures and Captions}

List of Figures and Captions.doc

\section{$\underline{\text { List of Figures and Captions }}$}

Figure 1: Details of the pultruded GFRP plates used in the tension joint tests [dimensions in mm]

Figure 2: Fixture for testing tension joints at ambient temperature: (a) front view and (b) side view

Figure 3: The temperature cabinet with a double-lap single-bolt joint set up in the modified test fixture prior to testing

Figure 4: Mean failure stresses of pultruded GFRP double-lap single-bolt tension joints as functions of: (a) joint geometry (E/D) and (b) test temperature $[\mathrm{W} / \mathrm{D}=4, \mathrm{D}=10 \mathrm{~mm}]$

Figure 5: Mean failure strains of pultruded GFRP double-lap single-bolt tension joints as functions of: (a) joint geometry $(\mathrm{E} / \mathrm{D})$ and test temperature $[\mathrm{W} / \mathrm{D}=4, \mathrm{D}=10 \mathrm{~mm}]$

Figure 6: Examples of the four dominant failure modes observed in the pultruded GFRP double-lap tension joint tests (a) shear $\left[\mathrm{E} / \mathrm{D}=2,20^{\circ} \mathrm{C}\right]$, (b) cleavage $\left[\mathrm{E} / \mathrm{D}=4,40{ }^{\circ} \mathrm{C}\right]$, (c) tension $\left[\mathrm{E} / \mathrm{D}=4,20{ }^{\circ} \mathrm{C}\right]$ and (d) bearing $\left[\mathrm{E} / \mathrm{D}=5,60{ }^{\circ} \mathrm{C}\right]$

Figure 7: Characteristic failure stresses of pultruded GFRP double-lap single-bolt tension joints as functions of: (a) joint geometry (E/D) and test temperature [W/D $=4, \mathrm{D}=10 \mathrm{~mm}]$

Figure 8: Characteristic failure strains of pultruded GFRP double-lap single-bolt tension joints as functions of: (a) joint geometry (E/D) and test temperature [W/D $=4, \mathrm{D}=10 \mathrm{~mm}]$ 
Figure 1

Figure 1 rev1.doc

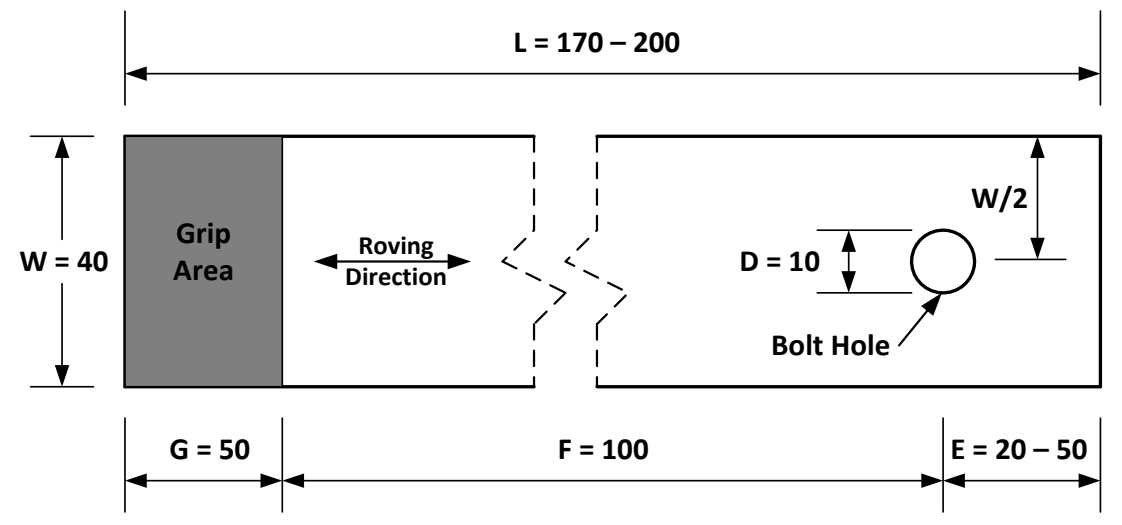

Figure 1 
Figures 2(a) \& 2(b))

Figures 2(a) \& 2(b).doc

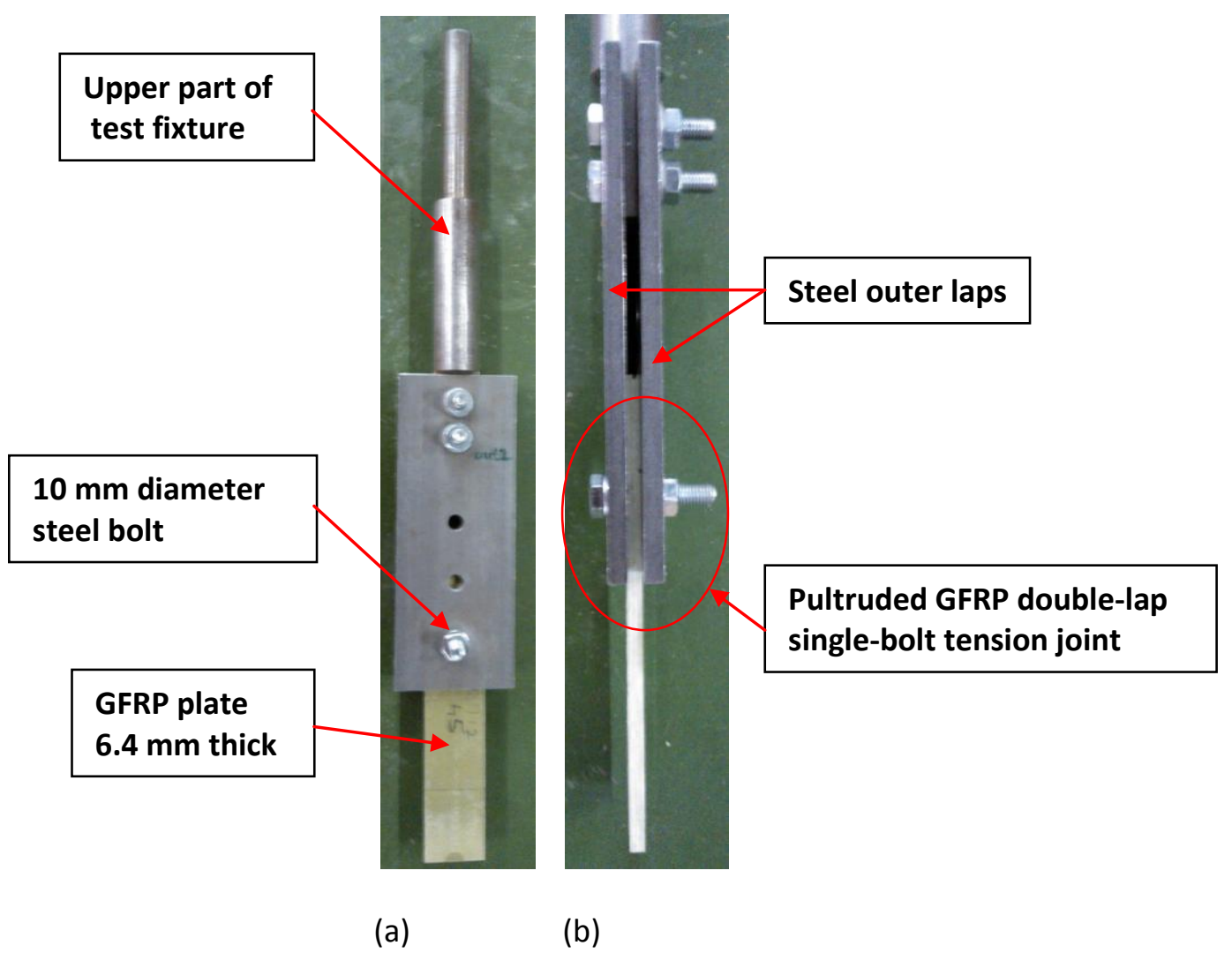

Figures 2(a) \& 2(b) 


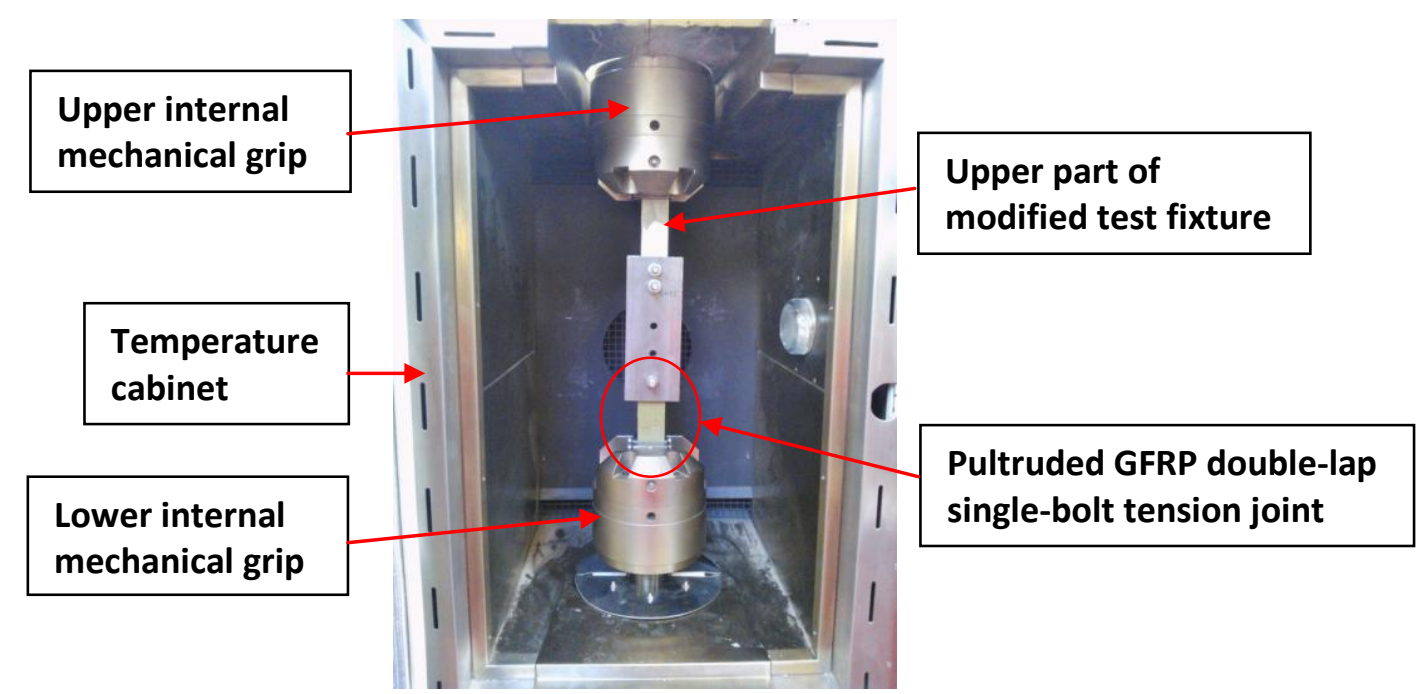

Figure 3 


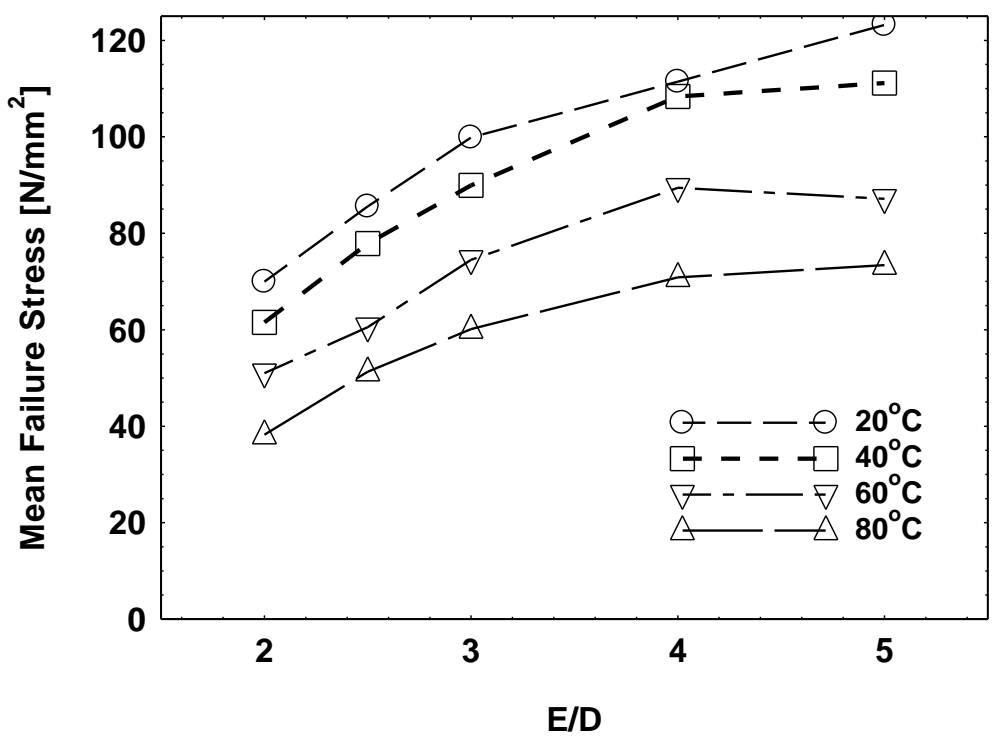

Figure 4(a) 


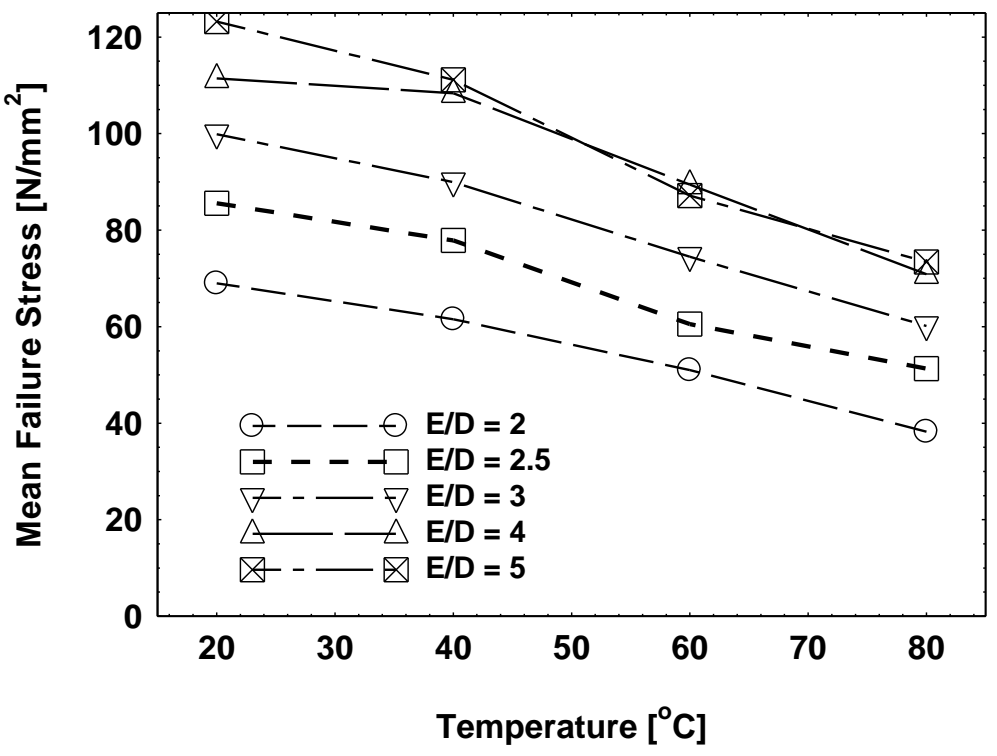

Figure 4(b) 


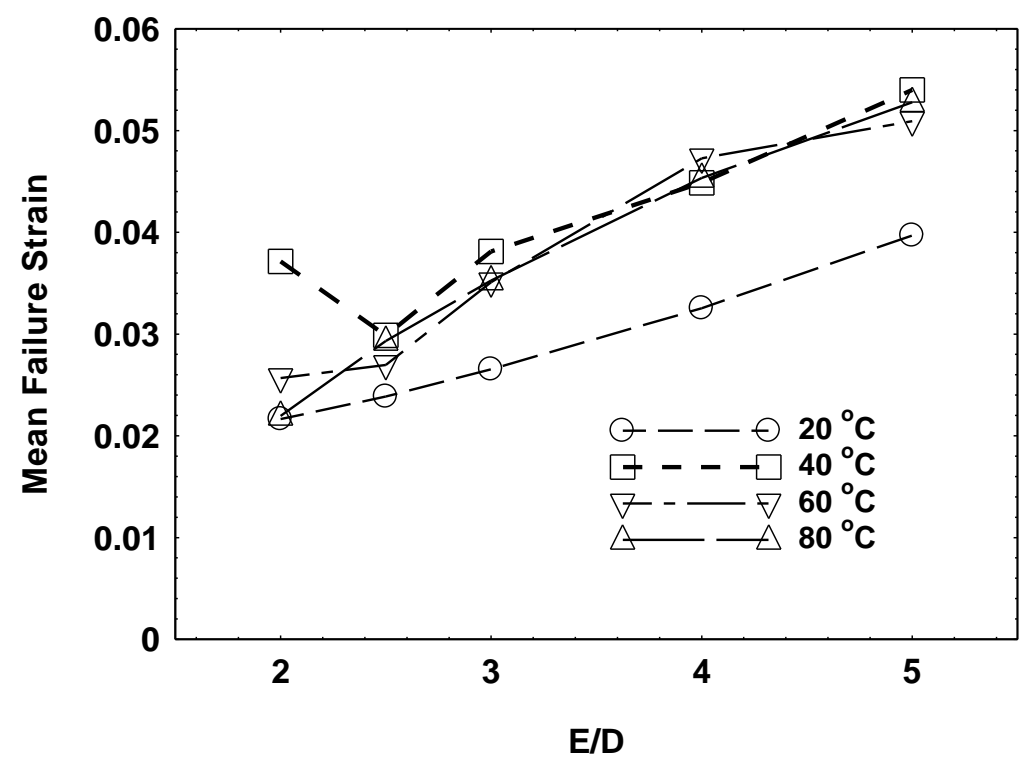

Figure 5(a) 


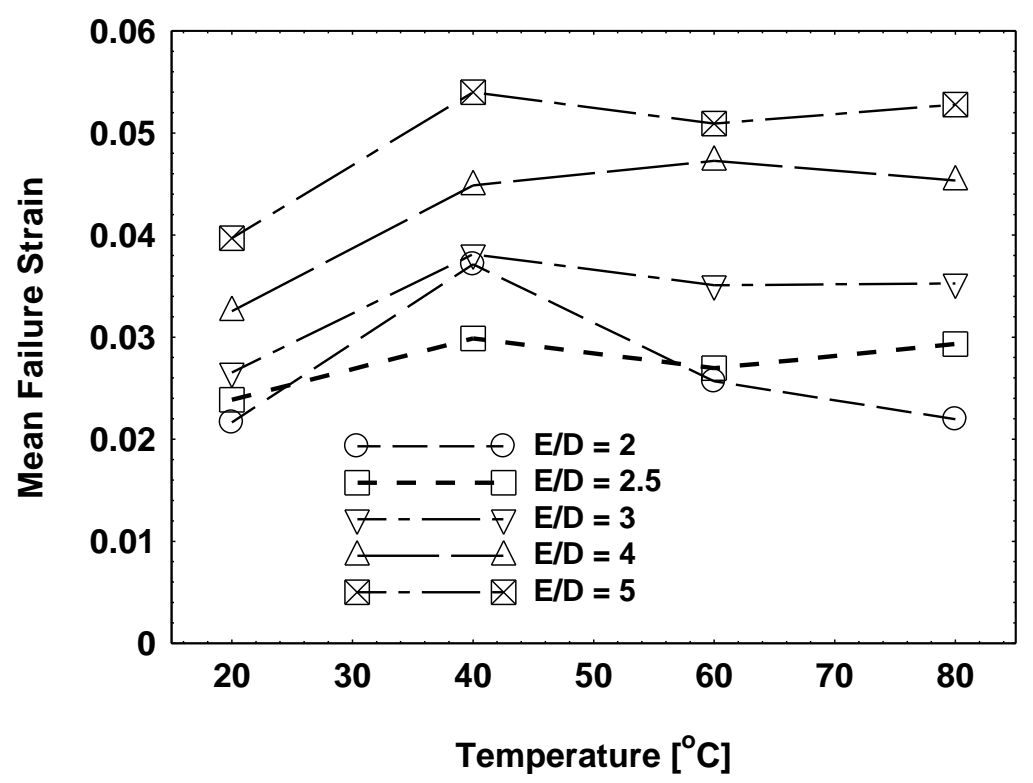

Figure 5(b) 
Shear failure planes

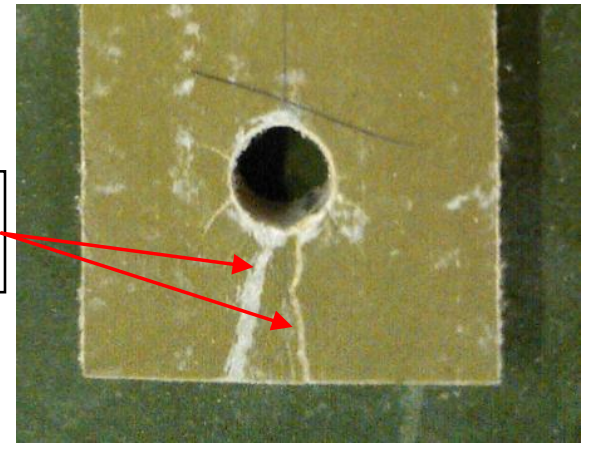

(a)

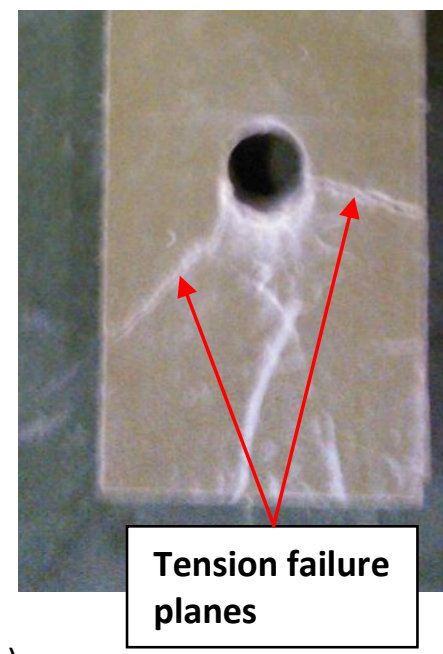

(c)

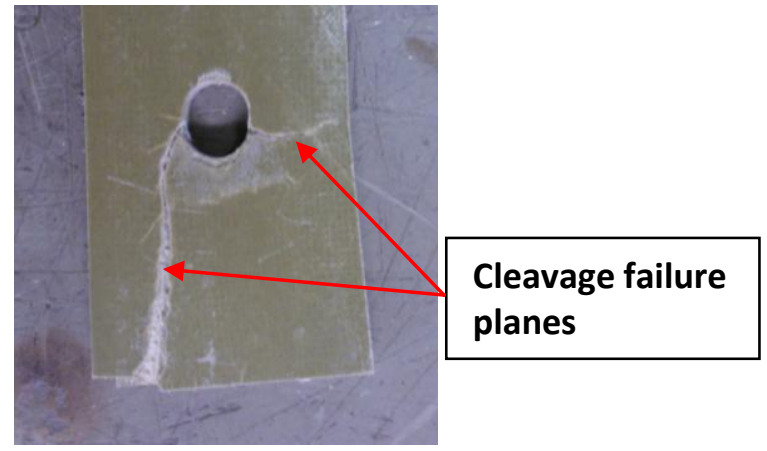

(b)

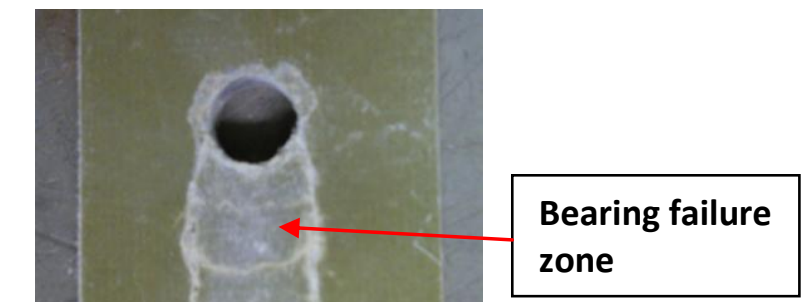

Figure 6

zone

(d) 


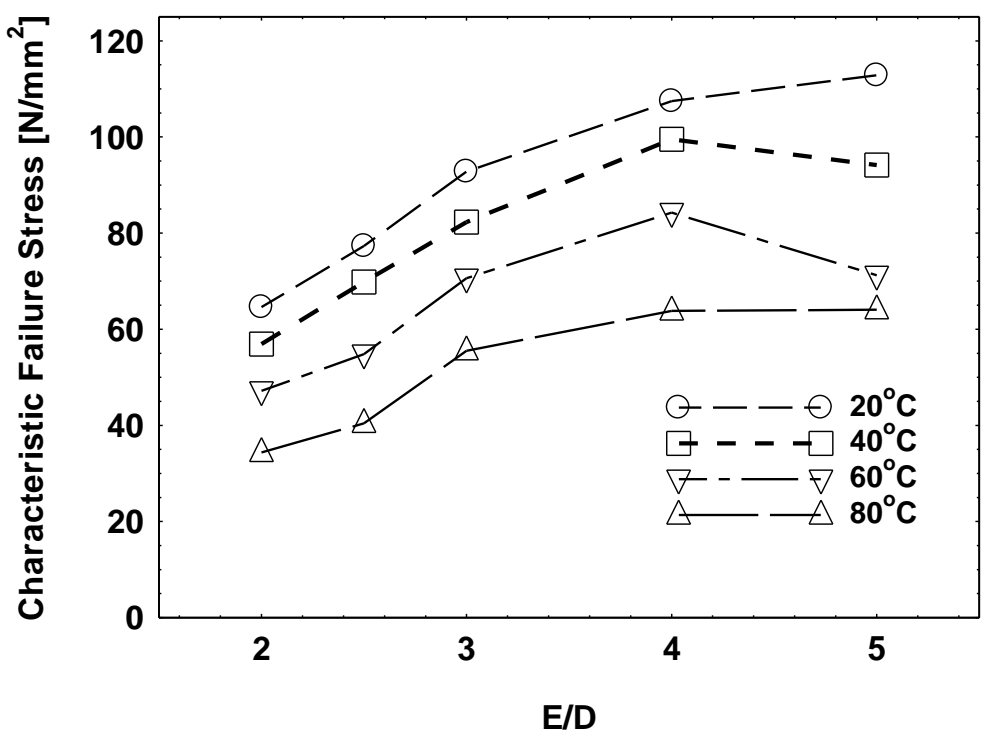

Figure 7(a) 


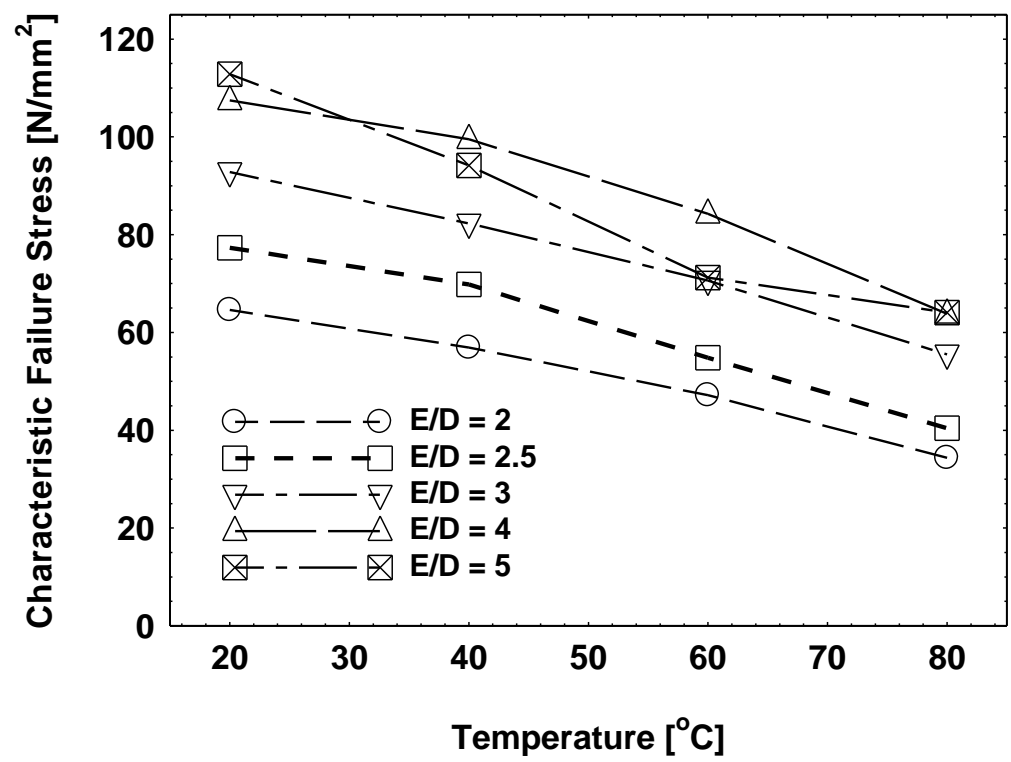

Figure 7(b) 


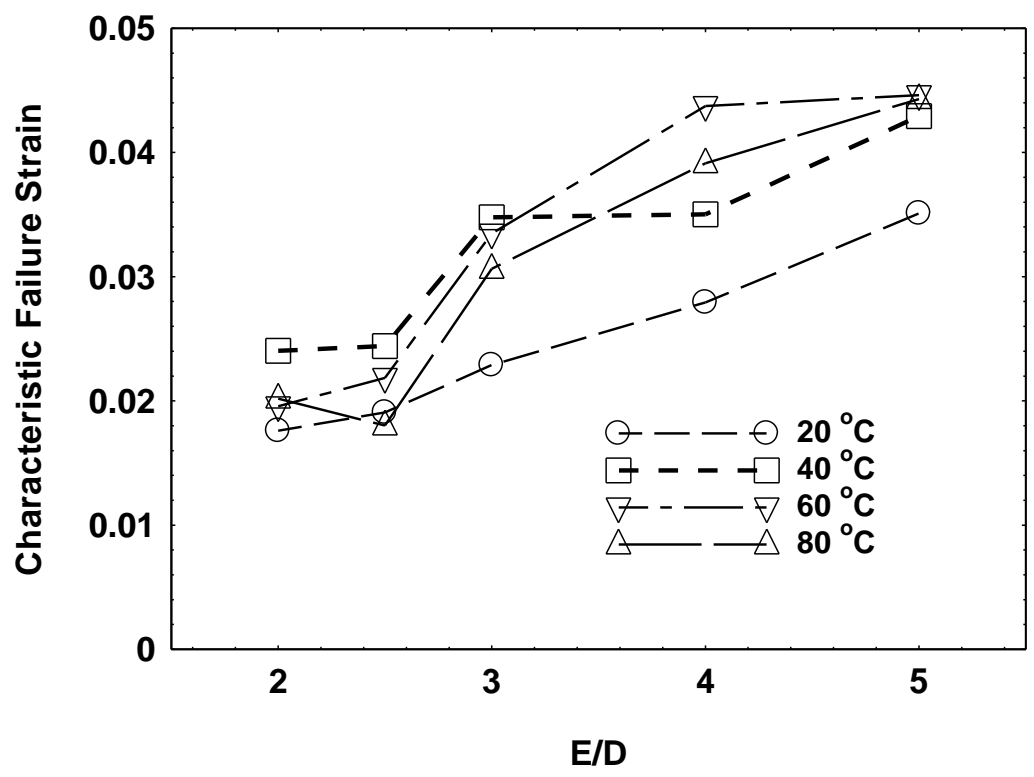

Figure 8(a) 


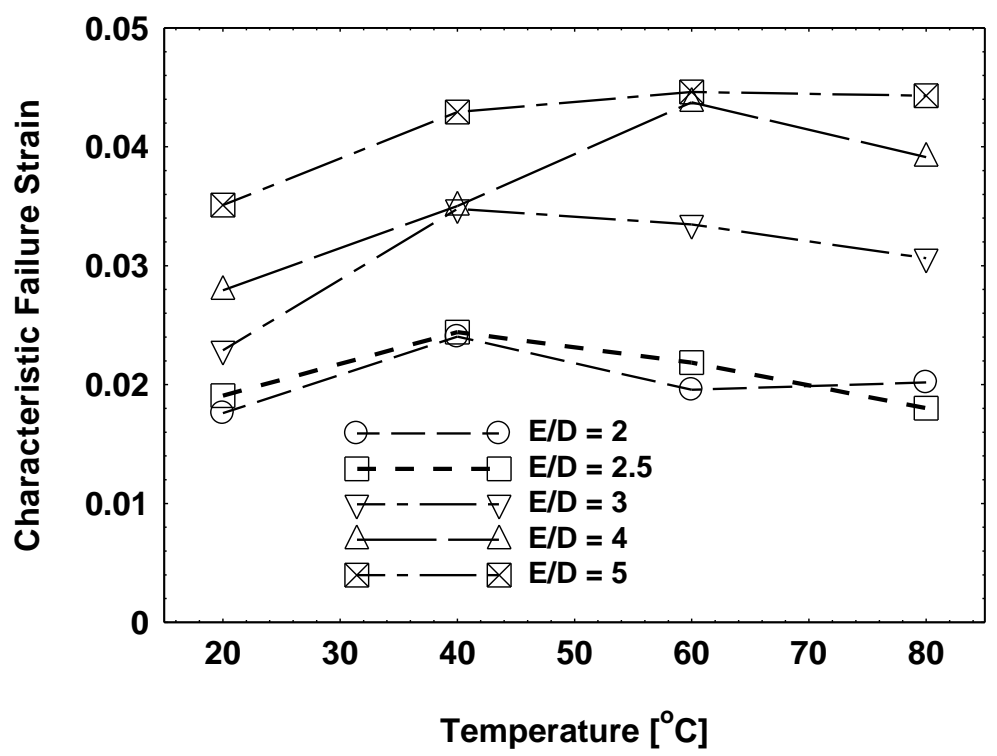

Figure 8(b) 


\section{List of Tables and Titles}

List of Tables rev1.doc

\section{$\underline{\text { List of Tables }}$}

Table 1: Joint geometries and test temperatures selected for the double-lap single-bolt tension joint tests

Table 2: Double-lap single-bolt tension joints in pultruded GFRP plate - mean values of cross-sectional areas, failure loads and overall extensions [W/D $=4, \mathrm{D}=10 \mathrm{~mm}$ ]

Table 3: Knock-down factors for the mean failure stresses of double-lap single-bolt tension joints in $6.4 \mathrm{~mm}$ pultruded GFRP plate [W/D $=4, \mathrm{D}=10 \mathrm{~mm}]$

Table 4: Knock-down factors for the characteristic failure stresses of double-lap single-bolt tension joints in $6.4 \mathrm{~mm}$ pultruded GFRP plate [W/D $=4, \mathrm{D}=10 \mathrm{~mm}]$ 


\section{Table 1}

Joint geometries and test temperatures selected for the double-lap single-bolt tension joint tests

\begin{tabular}{|c|c|c|c|c|c|}
\hline $\begin{array}{c}\text { Hole and Bolt } \\
\text { Diameters } \\
(\mathbf{D})\end{array}$ & $\begin{array}{c}\text { Plate Width to } \\
\text { Hole Diameter } \\
\text { Ratio }\end{array}$ & $\begin{array}{c}\text { End Distance } \\
\text { to Hole } \\
\text { Diameter } \\
\text { Ratios } \\
(\mathbf{m m})\end{array}$ & $\begin{array}{c}\text { Test } \\
\text { Temperatures }\end{array}$ & $\begin{array}{c}\text { Number of } \\
\text { Joints Tested } \\
\text { in each } \\
\text { (E/D) } \\
\text { G'C) }\end{array}$ & $\begin{array}{c}\text { Total Number } \\
\text { of Joints } \\
\text { Tested }\end{array}$ \\
\hline 10 & 4 & $2,2.5,3,4,5$ & RT $^{*}, 40,6080$ & 6 & 120 \\
\hline
\end{tabular}

*RT denotes room temperature (circa $20{ }^{\circ} \mathrm{C}$ ) 
Table 2

Double-lap single-bolt tension joints in pultruded GFRP plate - mean values of cross-sectional areas, failure loads and overall extensions [W/D $=4, \mathrm{D}=10 \mathrm{~mm}$ ]

\begin{tabular}{|c|c|c|c|c|}
\hline $\begin{array}{c}\text { Test } \\
\text { Temperature }\end{array}$ & $\begin{array}{c}\text { End } \\
\text { Distance to } \\
\text { Bolt/Hole } \\
\text { Ratio } \\
\text { (E/D) }\end{array}$ & $\begin{array}{c}\text { Mean Cross- } \\
\text { Sectional } \\
\text { Area and } \\
\text { (Standard } \\
\text { Deviation) } \\
\left(\mathbf{m m}^{2}\right) \\
\end{array}$ & $\begin{array}{c}\text { Mean Failure } \\
\text { Load and } \\
\text { (Standard } \\
\text { Deviation) } \\
(\mathrm{kN}) \\
\end{array}$ & $\begin{array}{c}\text { Mean } \\
\text { Extension at } \\
\text { Failure }\end{array}$ \\
\hline \multirow{5}{*}{20} & 2 & $256.0(2.259)$ & $17.97(0.636)$ & 2.165 \\
\hline & 2.5 & $255.4(2.434)$ & $21.85(1.174)$ & 2.387 \\
\hline & 3 & $257.2(1.615)$ & $25.69(1.036)$ & 2.653 \\
\hline & 4 & $254.7(1.526)$ & $28.38(0.411)$ & 3.253 \\
\hline & 5 & $256.0(2.107)$ & $31.67(1.585)$ & 3.968 \\
\hline \multirow{5}{*}{40} & 2 & $253.0(2.182)$ & $15.60(0.680)^{*}$ & $3.714 *$ \\
\hline & 2.5 & $256.8(4.967)$ & $19.38(0.625)$ & 2.988 \\
\hline & 3 & $257.6(1.230)$ & $23.19(1.085)$ & 3.812 \\
\hline & 4 & $254.7(2.598)$ & $27.55(1.188)^{*}$ & $4.486^{*}$ \\
\hline & 5 & $254.0(1.928)$ & $28.18(2.558)$ & $5.400 *$ \\
\hline \multirow{5}{*}{60} & 2 & $256.0(1.410)$ & $13.06(0.547)$ & 2.568 \\
\hline & 2.5 & $262.5(4.601)$ & $15.88(0.814)$ & 2.695 \\
\hline & 3 & $256.3(1.479)$ & $19.09(0.535)$ & 3.51 \\
\hline & 4 & $257.6(1.291)$ & $23.03(0.705)$ & 4.728 \\
\hline & 5 & $260.2(2.625)$ & $22.68(2.310)$ & 5.092 \\
\hline \multirow{5}{*}{80} & 2 & $256.7(1.930)$ & $9.81(0.487)^{*}$ & $2.196^{*}$ \\
\hline & 2.5 & $258.5(2.437)$ & $13.26(1.654)$ & 2.932 \\
\hline & 3 & $260.5(0.912)$ & $15.68(0.650)^{*}$ & $3.526^{*}$ \\
\hline & 4 & $264.3(4.304)$ & $18.72(0.896)$ & 4.533 \\
\hline & 5 & $255.0(0.591)$ & $18.71(1.367)$ & 5.277 \\
\hline
\end{tabular}

*Indicates that only five of the six nominally identical tests gave consistent results. 


\section{Table 3}

Knock-down factors for the mean failure stresses of double-lap single-bolt tension joints in 6.4 mm pultruded GFRP plate $[\mathrm{W} / \mathrm{D}=4, \mathrm{D}=10 \mathrm{~mm}]$

\begin{tabular}{|c|c|c|c|c|}
\hline \multirow{2}{*}{$\begin{array}{c}\text { Joint Geometry } \\
\text { (E/D) }\end{array}$} & \multicolumn{4}{|c|}{ Test Temperatures } \\
\cline { 2 - 5 } & $\mathbf{2 0}^{\mathbf{C}} \mathbf{C}$ & $\mathbf{4 0}^{\mathbf{0}} \mathbf{C}$ & $\mathbf{6 0}^{\mathbf{0}} \mathbf{C}$ & $\mathbf{8 0}^{\mathbf{0}} \mathbf{C}$ \\
\hline 2 & 0.234 & 0.206 & 0.170 & 0.128 \\
\hline 2.5 & 0.286 & 0.260 & 0.202 & 0.171 \\
\hline 3 & 0.334 & 0.301 & 0.249 & 0.201 \\
\hline 4 & 0.372 & 0.362 & 0.299 & 0.237 \\
\hline 5 & 0.412 & 0.372 & 0.291 & 0.245 \\
\hline
\end{tabular}


Table 4

Knock-down factors for the characteristic failure stresses of double-lap single-bolt tension joints in $6.4 \mathrm{~mm}$ pultruded GFRP plate [W/D = 4, D = $10 \mathrm{~mm}$ ]

\begin{tabular}{|c|c|c|c|c|}
\hline \multirow{2}{*}{$\begin{array}{c}\text { Joint Geometry } \\
\text { (E/D) }\end{array}$} & \multicolumn{4}{|c|}{ Test Temperatures } \\
\cline { 2 - 5 } & $\mathbf{2 0}^{\mathbf{}} \mathbf{C}$ & $\mathbf{4 0}^{\mathbf{0}} \mathbf{C}$ & $\mathbf{6 0}^{\mathbf{0}} \mathbf{C}$ & $\mathbf{8 0}^{\mathbf{0}} \mathbf{C}$ \\
\hline 2 & 0.242 & 0.213 & 0.177 & 0.129 \\
\hline 2.5 & 0.289 & 0.261 & 0.205 & 0.151 \\
\hline 3 & 0.348 & 0.308 & 0.264 & 0.208 \\
\hline 4 & 0.403 & 0.373 & 0.316 & 0.239 \\
\hline 5 & 0.423 & 0.353 & 0.267 & 0.240 \\
\hline
\end{tabular}

